\title{
Electrodeposition of Platinum Nanoparticles on Polyaniline Modified Electrode and its Electrocatalytic Activity towards the Oxidation of Methanol
}

\author{
ALI PARSA*, SEYED AMIR MIRSHAFIEYAN, AZADEH SHAKERI \\ and SARA AMANZADEH-SALOUT \\ Department of Chemistry, College of Science, Yadegar -e- Imam Khomeini (RAH) \\ Shahre-rey Branch, Islamic Azad University, Tehran, Iran. \\ *Corresponding author E-mail: aliparsa@iausr.ac.ir \\ http://dx.doi.org/10.13005/ojc/320410
}

(Received: June 10, 2016; Accepted: July 17, 2016)

\begin{abstract}
In this research, we reported the electrosynthesis of platinum nanoparticles on Polyaniline (PAni) modified electrode. The modified electrodes were prepared by incorporation of aniline and platinum salt $\left[\mathrm{H}_{2}\left(\mathrm{PtCl}_{6}\right), 6 \mathrm{H}_{2} \mathrm{O}\right]$ in phosphoric acid medium with $\mathrm{KCl}$ solution on composite graphite (CG) surface via cyclic voltammetry (CV) method. The synthesized platinum nanoparticles were characterized by using scanning electronic microscopy (SEM) and energy dispersive X-ray spectroscopy (EDX). The electro oxidation of methanol was investigated at the surface of these modified electrodes using CV method. It was found that methanol was oxidized with platinum embedded on the surface of PAni modified electrodes during the anodic potential sweep. Moreover, several impact factors such as scan rate, potential and concentration of methanol were studied on the oxidation of methanol toward electrosynthesized electrodes.
\end{abstract}

Keyword: Electrodeposition; Electrocatalytic oxidation; Platinum nanoparticle; Methanol; Polyaniline.

\section{INTRODUCTION}

More demand for applying conducting polymers has led to improve the technology of synthesis them as the materials with wide applications. A thin film of conducting polymer on the electrode may improve the electro-catalytic activity and so, it may be increased ${ }^{1-6}$. The conducting polymers can also cause the easier charge transfer during the electrochemical oxidation of alcohols on Pt surface ${ }^{7}$. PAni is one of the most extensively studied conducting polymers due to its easy synthesis, high conductivity, environmental stability and reversible redox catalytic properties ${ }^{8-15}$. The metal nanoparticles, such as $\mathrm{Pt}$, on PAni modified electrode show catalytic properties for organic fuel oxidation ${ }^{16-19}$. Fuel cells are known as one of the best electrical power to obtain the electrical 
energy from the combustion of hydrogen or organic compounds, than other sources ${ }^{20-22}$. Up to know, $\mathrm{Pt}$ is a good catalyst for methanol oxidation, but, because of the poisoning by $\mathrm{CO}$ absorption it has low stability. Some research was accomplished to study of $\mathrm{CO}$ adsorption and Methanol oxidation on Pt electrodes modified by electrodeposition of PAni film ${ }^{23-25}$. In those researches PAni is specified as the context for electro oxidation of hydrogen and methanol by applying the metal catalysts because of increasing the catalytic area for incorporating the metallic particles ${ }^{26-28}$. The PAni/Pt nanoparticles electrode has exhibited excellent catalytic activity for methanol oxidation in various mediums ${ }^{27,29-32}$. In this research the Pt nanoparticles were electrodeposited on PAni/CG electrodes with the noble condition of synthesis (during and after the formation of PAni films in phosphoric acid medium and $\mathrm{KCl}$ supporting electrolyte), and the electrocatalytic oxidation of methanol on modified electrodes was investigated with the purpose of improving highly active sites of electrodes.

\section{MATERIALS AND METHODS}

Aniline (Merck, Germany) was distilled under low pressure in the atmosphere and liquid nitrogen at a temperature of $5 \stackrel{\circ}{\circ} \mathrm{C}$ until color was maintained. Methanol ( $\mathrm{MeOH})(\mathrm{BDH}$ Chemicals, UK) was also in pure form. The hexachloro platinic (IV) acid hexahydrate $\left[\mathrm{H}_{2}\left(\mathrm{PtCl}_{6}\right) 6 \mathrm{H}_{2} \mathrm{O}\right]$ (Sigma Chemicals, USA), potassium chloride (KCl) (Fluka

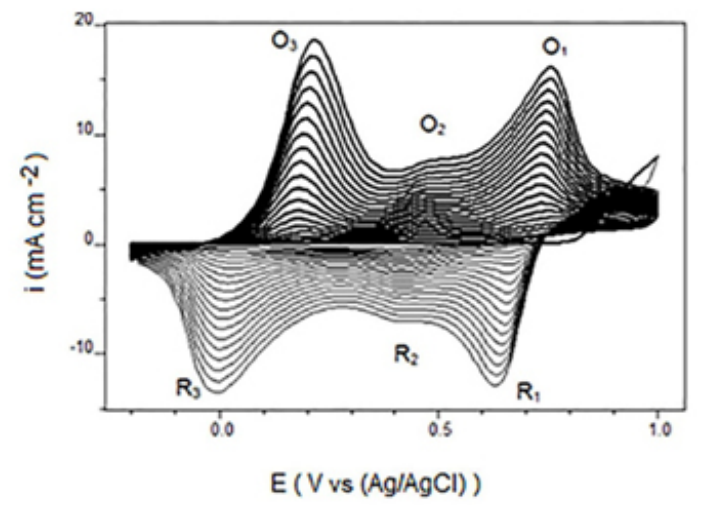

Fig. 1: CVs of $50 \mathrm{mM}$ Ani in $1 \mathrm{M} \mathrm{H}_{3} \mathrm{PO}_{4}$ containing $0.5 \mathrm{M} \mathrm{KCl}$ on CG electrode. The scan rate is $100 \mathrm{mVs}^{-1}$
Chemicals, Switzerland) and phosphoric acid $\left(\mathrm{H}_{3} \mathrm{PO}_{4}\right)$ (Sigma Chemicals, USA) were used without purification.

\section{Equipment}

The electrochemical analysis for the synthesis and characterization of nano-composite electrodes was carried out by a potentiostat/ galvanostat compactstat (Ivium Technologies, Netherlands). SEM, model VEGA Corporation (TESCAN) Czechoslovakia equipped with EDX detector has been used to investigate the morphology and size of the Pt nanoparticles on PAni modified electrodes. The composite 2B pencil graphite (CG) (o.d. $1.8 \mathrm{~mm}$ ) (Staedtler Lumograph, Germany) was used as working electrode against pseudo $\mathrm{Ag} / \mathrm{AgCl}$ reference electrode.

\section{Procedure}

The electrochemical synthesis of PAni was done by $50 \mathrm{mM}$ aniline in $10 \mathrm{~mL}$ of $1 \mathrm{M} \mathrm{H}_{3} \mathrm{PO}_{4}$ and $0.5 \mathrm{M} \mathrm{KCl}$ as a supporting electrolyte, on the working electrode (CG) by sweeping the potential continuously between $-0.2 \mathrm{~V}$ to $+1.00 \mathrm{~V} v \mathrm{v}$. $\mathrm{Ag} / \mathrm{AgCl}$ with a scan rate of $100 \mathrm{mVs}^{-1}$. Also the Pt particles were incorporated by electrochemical deposition from a solution containing $0.01 \%$ wt. $\left[\mathrm{H}_{2}\left(\mathrm{PtCl}_{6}\right)\right.$. $6 \mathrm{H}_{2} \mathrm{O}$ ] in $1 \mathrm{M} \mathrm{H}_{3} \mathrm{PO}_{4}$ on working electrode.

\section{RESULTS AND DISCUSSIONS}

\section{Electrodeposition \\ Electrodeposition of PAni on CG (PAni/CG)}

The cyclic voltammograms (CVs) for the deposition of PAni on CG electrode from the $50 \mathrm{mM}$
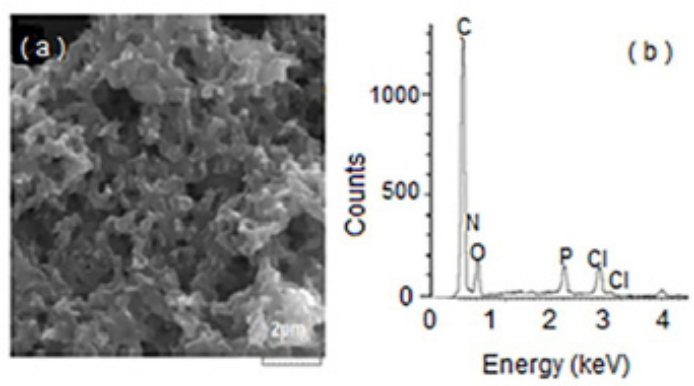

Fig. 2: SEM and EDX analysis of electrosynthesized PAni in $1 \mathrm{M} \mathrm{H}_{3} \mathrm{PO}_{4}$ containing $0.5 \mathrm{M} \mathrm{KCl}$ on CG electrode, (a) SEM (b) EDX 
aniline in aqueous medium of $10 \mathrm{~mL}$ of $1 \mathrm{M} \mathrm{H}_{3} \mathrm{PO}_{4}$ and $0.5 \mathrm{M} \mathrm{KCl}$ is shown in Fig.1. The three pairs of redox peaks are the result of aniline configuration conversions observed in the potential range of -0.2 $\mathrm{V}$ to $+1.0 \mathrm{~V}$. The first pair of redox peaks denoted as $\mathrm{O}_{3} / \mathrm{R}_{3}$ corresponds to the interconversion of the completely PAni reduced form, leucoemeraldine (LE) state, to the half-oxidized emeraldine base (EB) state. The second pair of redox peaks denoted as $O_{1} / R_{1}$ is due to oxidation of EB to the completely oxidized pernigraniline (PN) state and vice-versa. The $\mathrm{O}_{2} /$ $\mathrm{R}_{2}$ peaks are attributed to oxidation of segments of PAni chain to benzoquinone (Bq) species, whose peak potentials are very close to one another and tend to disappear after several successive scans ${ }^{33}$. Fig. 2a shows the surface morphology of PAni film on CG electrode. In the EDX analysis (Fig. $2 \mathrm{~b})$ the existence of phosphate ions is shown. This confirms that the doping of aniline with phosphate during polymerization has occurred on the surface of graphite electrode.

\section{Electrodeposition of Pt nanoparticles on PAni/ CG electrode (NPPt/PAni/CG)}

The Platinum nanoparticles were incorporated by electrochemical deposition on PAni/CG electrode from $\mathrm{H}_{2} \mathrm{PtCl}_{6} 6 \mathrm{H}_{2} \mathrm{O}$ solution $(0.01 \% \mathrm{w} / \mathrm{w})$ containing $1 \mathrm{M} \mathrm{H}_{3} \mathrm{PO}_{4}$ and $0.5 \mathrm{M} \mathrm{KCl}$ (Fig. 3). The CVs reveal one pair of redox peaks that represent the electrodeposition of $\mathrm{Pt}(\mathrm{IV})$ to metallic Pt on the surface of PAni/CG film in accordance with reaction (1) ${ }^{27}$.

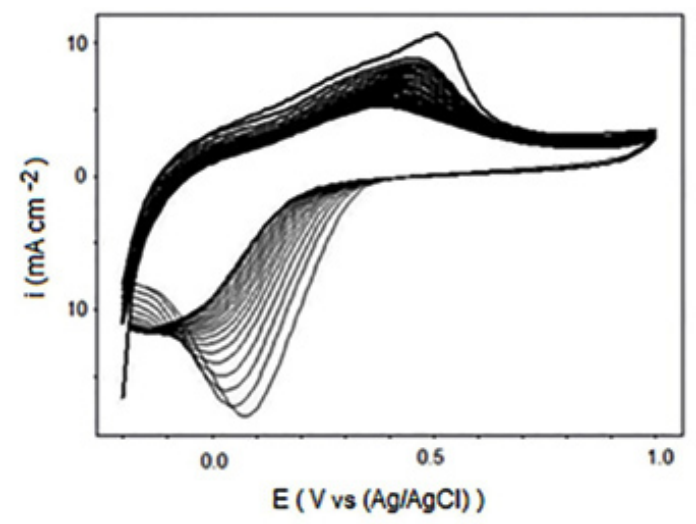

Fig. 3: The cyclic voltammogram obtained during electrodeposition of Pt nanoparticles on (PAni/CG) electrode in $1 \mathrm{M} \mathrm{H}_{3} \mathrm{PO}_{4}$ containing $0.5 \mathrm{M} \mathrm{KCl}$. The scan rate is $100 \mathrm{mVs}^{-1}$.
$\mathrm{PtCl}_{6}^{-2}+4 \mathrm{e}^{-} \rightarrow \mathrm{Pt}+6 \mathrm{Cl}^{-}$

Fig. 4a shows a fully homogenized surface of electrode. This confirms that distribution of Pt on PAni film is completely uniform. Also it shows the Pt nanoparticles on the PAni/CG electrode (Fig. 4b). EDX spectrum confirms the uniform presence of $\mathrm{Pt}$ nanoparticles on the surface of electrode (Fig. 4c).

\section{Simultaneous electrodeposition of Pt and PAni on CG (Pt-PAni/CG)}

The platinum nanoparticles and PAni were, simultaneously, electrodeposited on CG from a solution of $\mathrm{H}_{2} \mathrm{PtCl}_{6} 6 \mathrm{H}_{2} \mathrm{O}(0.01 \% \mathrm{w} / \mathrm{w}), 50 \mathrm{mM}$ aniline, $1 \mathrm{M} \mathrm{H}_{3} \mathrm{PO}_{4}$ and $0.5 \mathrm{M} \mathrm{KCl}$. As shown in Fig. 5 the CVs have two redox peaks. In this case, it is seen that PAni is in the conducting emeraldine salt (ES) form which undergoes the oxidation to the PN form, providing electrons for the reduction of $\mathrm{PtCl}_{6}{ }^{-2}$ to metallic Pt.

Fig. 6a and $\mathrm{b}$ shows that, spherical Pt is in context with PAni after the simultaneous deposition. As compared to NPPt/PAni/CG, the distribution and dispersal is less. The absence of $\mathrm{Pt}$ in depth of 4 microns was confirmed by EDX analysis (Fig. 6c). As is evident the nanostructure can be changed with monomer displacement, i.e., the conductivity of PAni

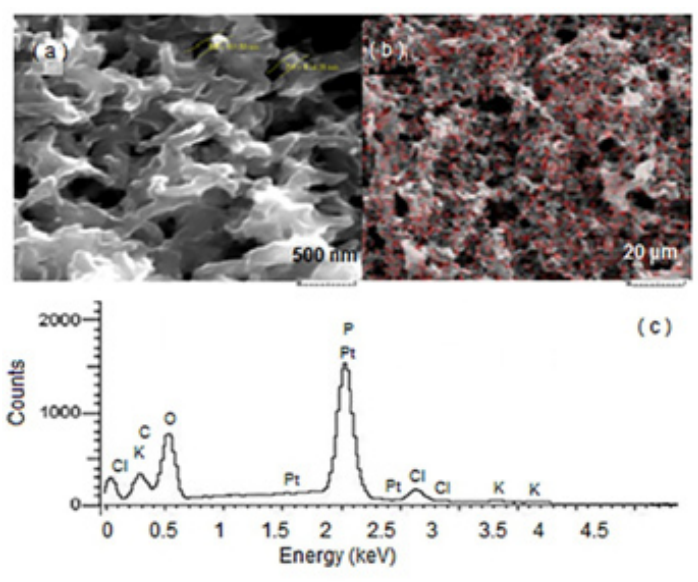

Fig. 4. SEM and EDX analysis of $P t$ nanoparticles on modified (NPPt/PAni/CG) electrode in $1 \mathrm{M} \mathrm{H}_{3} \mathrm{PO}_{4}$ containing $0.5 \mathrm{M} \mathrm{KCl}$. (a) and (b) SEM image of (NPPt/PAni/CG) electrode at different magnifications (c) EDX analysis of Pt nanoparticles on (PAni/CG) electrode 
can play important role in doping and polymerizing of PAni with platinum ions. This result may also be attributed to the higher conductivity and faster charge transfer of PAni film in the intermediate oxidation state. It must be pointed out that the catalytic current is greatly in-creased with increase in the amount of deposited $\mathrm{Pt}{ }^{34}$.

Electrocatalytic oxidation of methanol

Fig. 7a and b shows the CVs of Pt-PAni/ $\mathrm{CG}$ and NPPt/PAni/CG electrodes in $1 \mathrm{M} \mathrm{H}_{3} \mathrm{PO}_{4}$

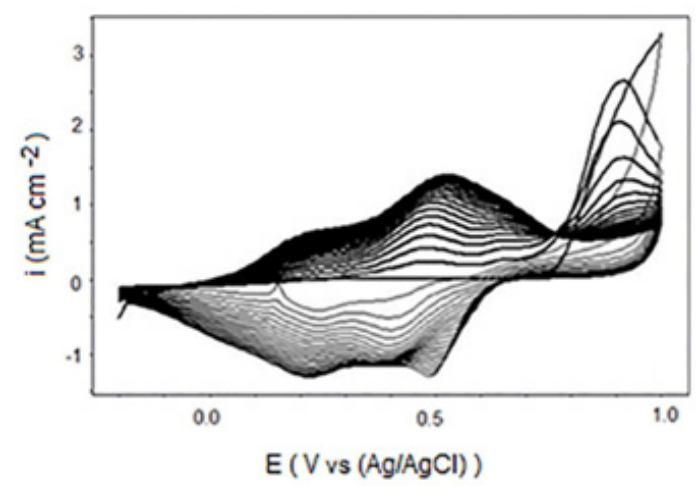

Fig. 5: Cyclic voltammogram of Simultaneous electrosynthesis of Pt nanoparticles and PAni at on CG electrode in a solution of $1 \mathrm{M} \mathrm{H}_{3} \mathrm{PO}_{4}$ containing $0.5 \mathrm{M} \mathrm{KCl}, \mathrm{H}_{2} \mathrm{PtCl}_{6} 6 \mathrm{H}_{2} \mathrm{O}(0.01 \% \mathrm{w} / \mathrm{w})$ and $50 \mathrm{mM}$ aniline. The scan rate is $100 \mathrm{mVs}^{-1}$

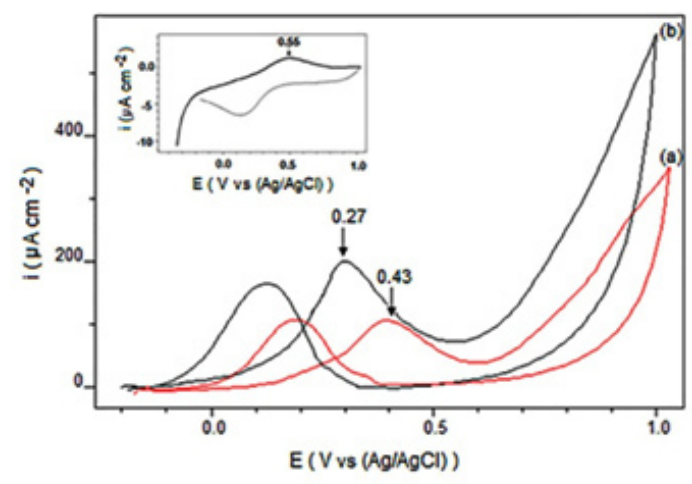

Fig. 7: CVs of, (a) (Pt-PAni/CG) and (b), (NPPt/ PAni/CG) electrodes in $1 \mathrm{M} \mathrm{H}_{3} \mathrm{PO}_{4}$ solution containing $0.5 \mathrm{M}$ methanol at scan rate of 100 $\mathrm{mVs}^{-1}$. Inset: $\mathrm{CV}$ of unmodified CG electrode in $1 \mathrm{M} \mathrm{H}_{3} \mathrm{PO}_{4}$ solution and $0.5 \mathrm{M}$ methanol at scan rate of $100 \mathrm{mVs}^{-1}$ containing $0.5 \mathrm{M}$ methanol at a scan rate of 100 $\mathrm{mVs}^{-1}$, respectively. The methanol oxidations of Pt-PAni/CG in $\left(\mathrm{E}_{\mathrm{pa}}=0.43 \mathrm{~V}\right)$ and NPPt/PAni/CG in $\left(\mathrm{E}_{\mathrm{pa}}=0.27 \mathrm{~V}\right)$ indicate that NPPt/PAni/CG has a relatively superior electrocatalytic performance. The

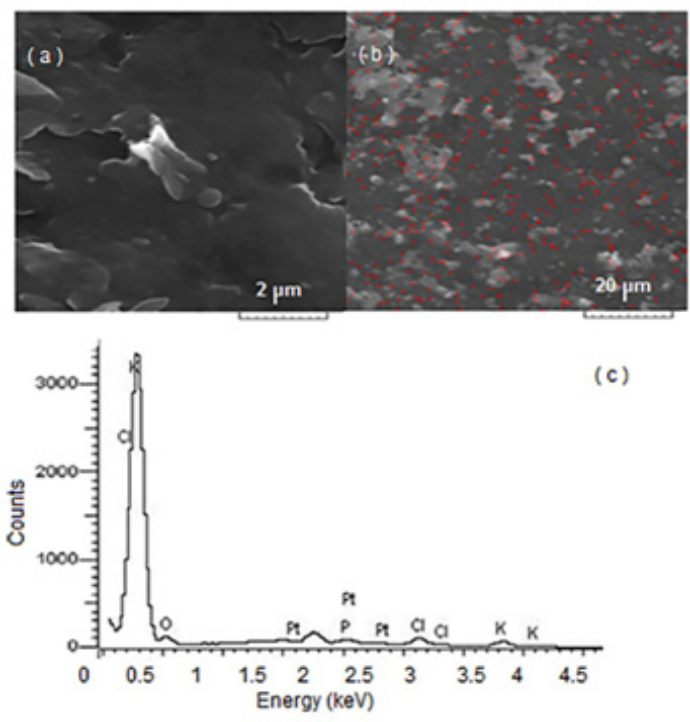

Fig. 6: SEM and EDX analysis of Pt nanoparticles on modified (Pt-PAni/CG) electrode in $1 \mathrm{M} \mathrm{H}_{3} \mathrm{PO}_{4}$ containing $0.5 \mathrm{M}$ $\mathrm{KCl}$. (a) and (b) SEM image of (Pt-PAni/CG) electrode at different magnifications (c) EDX analysis of (Pt-PAni/CG) electrode

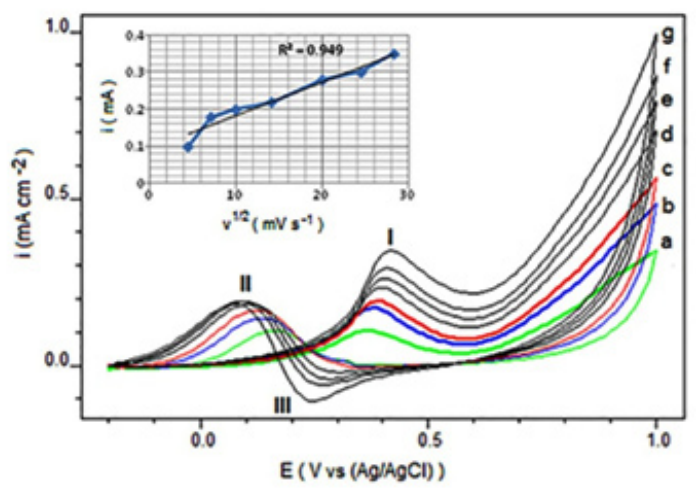

Fig. 8: CVs of (NPPt/PAni/CG) prepared in 1 $\mathrm{M} \mathrm{H}_{3} \mathrm{PO}_{4}$ and $0.5 \mathrm{M}$ methanol at different scan rates (a) 20, (b) 60, (c) 100, (d) 200, (e) 400, (f) 600 , (g) $800 \mathrm{mVs}-1$ in the potential range of -0.2 $\mathrm{V}$ to $1.0 \mathrm{~V}$. Inset the calibration plot of current vs. square root of scan rate 
Table 1: CVs data of (NPPt/PAni/CG) and (Pt-PAni/CG) electrode

\begin{tabular}{lcc}
\hline Electrode & $\begin{array}{c}\text { Charge of } \\
\mathbf{H}_{2} \text { absorption }\end{array}$ & $\begin{array}{c}\text { max anodic } \\
\text { peak current }\left(\mathbf{I}_{\mathrm{pa}}\right)\end{array}$ \\
\hline (NPPt/PAni/CG) & $3.14 \mathrm{mC} / \mathrm{cm}^{2}$ & $19.32 \mathrm{~mA} / \mathrm{cm}^{2}$ \\
(Pt-PAni/CG) & $2.07 \mathrm{mC} / \mathrm{cm}^{2}$ & $10.09 \mathrm{~mA} / \mathrm{cm}^{2}$ \\
\hline
\end{tabular}

electrochemical oxidation of methanol on Pt surface occurs in two steps ${ }^{35}$. . The first step is methanol dehydrogenation in which, methanol is oxidized to become adsorbed $\mathrm{CO}_{\text {ads }}$ species. The second step is the removal of $\mathrm{CO}_{\text {ads }}$ which proceeded via adsorbed $\mathrm{OH}_{\text {ads }}$ to produce $\mathrm{CO}_{2}$. The adsorbed $\mathrm{OH}_{\text {ads }}$ is produced from water dissociation process on $\mathrm{Pt}$ catalyst sites. The overall processes are summarized in reactions (below):

$$
\begin{aligned}
& \mathrm{CH}_{3} \mathrm{OH} \rightarrow \mathrm{CO}_{\mathrm{ads}}+4 \mathrm{H}^{+}+4 \mathrm{e}^{-} \\
& \mathrm{H}_{2} \mathrm{O} \rightarrow \mathrm{OH}_{\text {ads }}+\mathrm{H}^{+}+\mathrm{e}^{-} \\
& \mathrm{OH}_{\text {ads }}+\mathrm{CO}_{\text {ads }} \rightarrow \mathrm{CO}_{2}+\mathrm{H}^{+}+\mathrm{e}^{-}
\end{aligned}
$$

It is known that the integrated intensity of hydrogen absorption represents the number of Pt sites that are available for hydrogen adsorption and desorption ${ }^{25}$. To calculate the charge required for hydrogen absorption on the electrode surfaces, we assume that the double-layer charging current is constant over the whole potential range ${ }^{36}$. The charge required for hydrogen absorption on the NPPt/ $P A n i / C G$ surface is $3.14 \mathrm{mC} \mathrm{cm}{ }^{-2}$ which is 1.5 times larger than that required for hydrogen absorption on the Pt-PAni/CG surface $\left(2.07 \mathrm{mC} \mathrm{cm}^{-2}\right)$, (Table 1). Comparing the $\mathrm{CV}$ results of NPPt/PAni/CG with Pt-PAni/CG electrodes, have indicated a significantly higher oxidation current toward methanol oxidation for the NPPt/PAni/CG electrode. For instance, in Table 1, the maximum anodic peak current densities $\left(\mathrm{I}_{\mathrm{pa}}\right)$ for NPPt/PAni/CG and Pt-PAni/CG electrodes are $19.32 \mathrm{~mA} \mathrm{~cm}^{-2}$ and $10.09 \mathrm{~mA} \mathrm{~cm}^{-2}$, respectively. A high surface area for Pt particles in NPPt/PAni/CG is anticipated due to the uniform distribution of $\mathrm{Pt}$ particles into PAni which can twist up to form a spatial $3 \mathrm{D}$ dimensional matrix. In addition to this, the $-\mathrm{CO}_{2} \mathrm{H}$ groups in NPPt/PAni/CG may act as a stabilizer for Pt particles, preventing their aggregation. The PAni/ CG matrix acts as a good bed for the deposition of Pt particles, and increases the density of the active sites on the electrode surface.

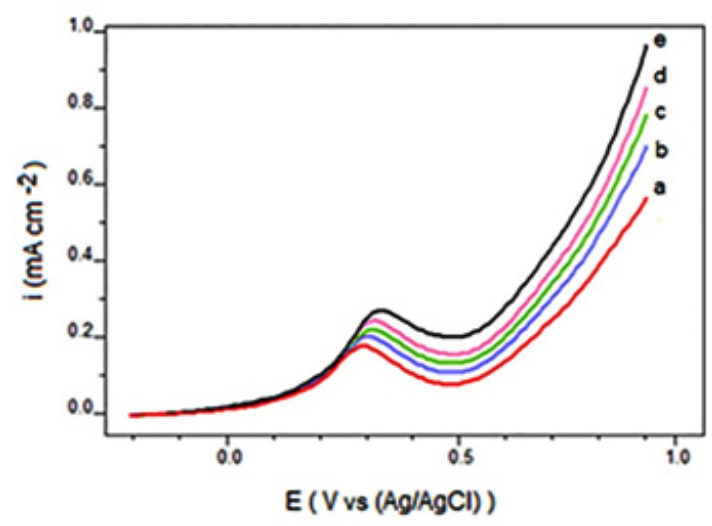

Fig. 9: LSVs of (NPPt/PAni/CG) prepared in $1 \mathrm{M}$ $\mathrm{H}_{3} \mathrm{PO}_{4}$ with different concentration of methanol

(a) $0.5 \mathrm{M}$, (b) $1 \mathrm{M}$, (c) $2 \mathrm{M}$, (d) $3 \mathrm{M}$, (e) $4 \mathrm{M}$ in potential range of $-0.2 \mathrm{~V}$ to $+1.0 \mathrm{~V}$

\section{Effect of scan rate on the oxidation of methanol} Figure $8 \mathrm{a}$ to $\mathrm{g}$ shows the CVs of NPPt/ PAni/CG in $1 \mathrm{M} \mathrm{H}_{3} \mathrm{PO}_{4}$ containing $0.5 \mathrm{M}$ methanol at the various scan rates and in the potential range of $-0.2 \mathrm{~V}$ to $1.0 \mathrm{~V}$. This indicates that, increasing the scan rate has led to increase the $\mathrm{I}_{\mathrm{pa}}$ and cause to improve the methanol oxidation. In the lower scan rates, i.e. less than $200 \mathrm{mVs}^{-1}$, two well define redox peaks are observed. The first $I_{p a}$ is produced due to the oxidation of freshly chemisorbed species coming from methanol adsorption. The second $\mathrm{I}_{\mathrm{pa}}$ is primarily associated with the removal of carbonaceous species not completely oxidized in forward scan rather than caused by freshly chemisorbed species. In the higher scan rates (more than $200 \mathrm{mVs}^{-1}$ ) there are three oxidation peaks, the second and third in the reverse scan is additional, which is due to a combination processes such as surface rearrangement and increase of the heterogeneous non-faradaic reaction rate $37,28,38$. The plot of $I_{p} v s$. square root of scan rate (inset) is linear, which is indicates that the electrochemical process was under diffusion control

\section{Effect of methanol concentration on electrocatalytic activity}

Figure $9 a$ to $d$ shows the linear sweep voltammograms (LSVs) of NPPt/PAni/CG in $1 \mathrm{M}$ $\mathrm{H}_{3} \mathrm{PO}_{4}$ containing different concentration of methanol at the potential range of $-0.2 \mathrm{~V}$ to1.0 $\mathrm{V}$. A significant enhancement of methanol oxidation has been 
observed at high concentration of methanol as shown by the increase of the oxidation peak current $\left(I_{p a}\right)$.

\section{CONCLUSION}

The platinum nanoparticles were successfully electrodeposited onto the surface of PAni/CG electrodes. The NPPt/PAni/CG electrode appeared to have well distribution and dispersal of Pt nanoparticles on the PAni film. The NPPt/PAni/CG electrode exhibited electrocatalytic activity toward methanol oxidation with a higher current density and at lower onset potential. In view of results, the higher concentrations of methanol and higher scan rates of potential have also enhanced the methanol oxidation. According to the extensive studies in this filed, still further research can complement and corroborate these results.

\section{ACKNOWLEDGEMENTS}

This work is supported by the Islamic Azad University, Yadegar -e- Imam Khomeini (RAH) Shahre-rey Branch, Tehran, Iran for Research University (RU) grant -1395/1742:90/07/27

\section{REFERENCES}

1. Su, N. Nanoscale Res. Lett. 2015, 10, 1-9 .

2. Campbell, D. K. Synth. Met. 2001, 125, 117128 .

3. Macdiarmid, A. G. Synth. Met. 1987, 21, 79-83

4. Wallace, G. G.; Smyth, M.; Zhao, H. TrAC, Trends Anal. Chem. 1999, 18, 245-251.

5. Lange, U.; Roznyatovskaya, N. V.; Mirsky, V. M. Anal. Chim. Acta. 2008, 614, 1-26.

6. Morteza, E.; Roya, D. Orient. J. Chem. 2015, 31, 1185-1189.

7. Serra, D.; McElwee-White, L. Inorg. Chim. Acta. 2008, 361, 3237-3246 .

8. MacDiarmid, A.; Chiang, J.; Richter, A.; Epstein, A. Synth. Met. 1987, 18, 285-290 .

9. MacDiarmid, A.; Yang, L.; Huang, W.; Humphrey, B. Synth. Met. 1987, 18, 393398.

10. Genies, E.; Boyle, A.; Lapkowski, M.; Tsintavis, C. Synth. Met. 1990, 36, 139-182 .

11. Luzny, W.;Banka, E.; Stochmal-Pomarzanska, E. X-Ray Investigations of Polymer Structures. 2000, 47-50.

12. Æiriæ-Marjanoviæ, G. Synth. Met. 2013, 177, 1-47.

13. Kajornkavinkul, S.; Punrat, E.; Siangproh, W.; Rodthongkum, N.; Praphairaksit, N.; Chailapakul, O. Talanta. 2016, 148, 655660.

14. Ameen, S.; Shaheerakhtar, M. Orient. J. Chem. 2013, 29, 837-860.

15. Udmale, V.; Mishr, D.; Gadhave, R.; Pinjare, D.; Yamgar, R. Orient. J. Chem. 2013, 29,
927-936 .

16. Han, Y.-K.; Chang, M.-Y.; Ho, K.-S.; Hsieh, T.-H.; Tsai, J.-L.; Huang, P.-C. Sol. Energy Mater. Sol. Cells. 2014, 128, 198-203 .

17. Farghali, A.; Moussa, M.; Khedr, M. J. Alloys Compd. 2010, 499, 98-103.

18. Abaci, S.; Nessark, B.; Boukherroub, R.; Lmimouni, K. Thin Solid Films. 2011, 519, 3596-3602 .

19. Lemos, H. G.; Santos, S. F.; Venancio, E. C. Synth. Met. 2015, 203, 22-30 .

20. Andújar, J.; Segura, F. Renew Sust Energ Rev. 2009, 13, 2309-2322.

21. Behling, N. H. Fuel Cells. 2013, 423-600 .

22. Sharma, R.; Kar, K. K. Electrochim. Acta. 2015, 156, 199-206.

23. Wang, Z.; Gao, G.; Zhu, H.; Sun, Z.; Liu, H.; Zhao, X. Int. J. Hydrogen Energy. 2009, 34, 9334-9340.

24. Yan, R.; Jin, B. Electrochim. Acta. 2014, 115, 449-453.

25. Gyenge, E. PEM Fuel Cell Electrocatalysts and Catalyst Layers. 2008, 165-287 .

26. Lei, X.; Guo, X.; Zhang, L.; Wang, Y.; Su, Z. J. Appl. Polym. Sci. 2007, 103, 140-147 .

27. Sugano, Y.; Yoshikawa, H.; Saito, M.; Tamiya, E. Electrochim. Acta. 2011, 56, 9875-9882 .

28. Stejskal, J.; Sapurina, I.; Trchová, M. Prog. Polym. Sci. 2010, 35, 1420-1481.

29. O'Mullane, A. P.; Dale, S. E.; Day, T. M.; Wilson, N. R.; Macpherson, J. V.; Unwin, P. R. J. Solid State Electrochem. 2006, 10, 792-807 .

30. Hong, T.-Z.; Xue, Q.; Yang, Z.-Y.; Dong, Y.-P. 
J. Power Sources. 2016, 303, 109-117 .

31. Wang, M.; Song, X.; Yang, Q.; Hua, H.; Dai, S.; Hu, C.; Wei, D. J. Power Sources. 2015, 273, 624-630.

32. Wang, Z.; Shi, G.; Zhang, F.; Xia, J.; Gui, R.; Yang, M.; Bi, S.; Xia, L.; Li, Y.; Xia, L.; Xia, Y. Electrochim. Acta. 2015, 160, 288-295 .

33. Parsa, A.; Ab Ghani, S. Polymer. 2008, 49, 3702-3708 .

34. Cai, L.; Chen, H. J. Appl. Electrochem. 1998, 28, 161-166.
35. Tripkoviæ, A. V.; Popoviæ, K. D.; Loviæ, J.; Jovanoviæ, V.; Kowal, A. J. Electroanal. Chem. 2004, 572, 119-128.

36. Wu, T.-Y.; Li, W.-B.; Kuo, C.-W.; Chou, C.-F.; Liao, J.-W.; Chen, H.-R.; Tseng, C.-G. International Journal of Electrochemical Science. 2013, 10720-10732.

37. Singh, R.; Awasthi, R.; Tiwari, S. Open Catal. J. 2010, 3, 54-61.

38. Prabakar, S. J. R.; Kim, Y.; Jeong, J.; Jeong, S.; Lah, M. S.; Pyo, M. Electrochim. Acta. 2016, 188, 472-479. 